(2) Open Access Full Text Article

\title{
Fear and Anxiety Associated with Cataract Surgery Under Local Anesthesia in Adults: A Systematic Review
}

\section{Iwona Obuchowska $\mathbb{D}$ Joanna Konopinska}

Department of Ophthalmology, Medical University of Bialystok, Bialystok, Poland
Correspondence: Joanna Konopinska Department of Ophthalmology, Medical University of Białystok, M. SklodowskaCurie 24A, Białystok, 15-276, Poland $\mathrm{Tel} / \mathrm{Fax}+48857468372$

Email joannakonopinska@o2.pl

\begin{abstract}
Cataract surgery is one of the most frequently performed surgical procedures worldwide. Patients usually experience strong negative emotions, such as fear and anxiety. A systematic review of the recent literature regarding the emotional states experienced during cataract surgery under local anaesthesia was performed based on the PubMed and Scopus databases. The objective of this review was to determine the causes and frequency of fear and anxiety, as well as methods for improving intraoperative experience and supporting the patient prior to surgery. Anxiety is mainly caused by fear of the surgery itself, fright of pain, and loss of vision. Abstaining and visual sensations experienced during cataract surgery also increased the preoperative anxiety. Women and hypochondriacs showed higher levels of anxiety. The greatest intensity of negative emotions occurred on the day of the cataract surgery. Patients operated on both eyes experienced greater fear and anxiety before the operation of the first eye surgery. In order to reduce patients' negative experiences, pharmacological sedation, preoperative education and counselling, manual massage immediately before surgery, and listening to music during surgery are used. Taking this information into consideration allows the introduction of effective methods of eliminating the patient's negative feelings in connection with cataract surgery, which leads to an improvement in the results of the operation and an increase in the patients' sense of satisfaction and quality of life.
\end{abstract}

Keywords: sedation, preoperative counseling, phacoemulsification, patients' emotions, quality of life

\section{Plain Language Summary}

Cataract surgery most often is performed under the local anesthesia. These caused anxiety and fear on the operated patients. Pharmacological sedation is not always allowed due to general diseases, so there is a need for providing data of another ways to alleviate patients negative emotions. There are several effective methods of achieving this aim: preoperative education and counselling, manual massage immediately before surgery, and listening to music during surgery are used. Applying these techniques leads to an improvement in the results of the operation and an increase in the patients' sense of satisfaction and quality of life.

\section{Introduction}

Cataract is the leading cause of blindness worldwide, and its removal is currently one of the most frequently performed surgical procedures. ${ }^{1}$ Adult cataract surgery is performed under local anaesthesia: retrobulbar, peribulbar, and sub-Tenon's 
blocks or topical anaesthesia. General anaesthesia is used only in extreme cases. Most surgeons do not recommend taking sedatives prior to cataract surgery, as it may affect the patient's state of consciousness, mental clarity, and time of reaction. Cataract surgery is performed on conscious patients who can actively and consciously communicate, but can also experience anxiety and fear. Knowledge about the influence of emotional factors, such as stress, fear, and anxiety, on the course of cataract surgery as well as on the eye healing process is of great importance. By introducing effective methods of eliminating or weakening the action of these factors, it is possible to improve the outcome of the surgery, as well as the patient's satisfaction and quality of life.

\section{Materials and Methods}

This systematic review was conducted and reported based on the Preferred Reporting Items for Systematic Reviews and Meta-Analyses (PRISMA) Statement and the PRISMA network meta-analysis extension statement. ${ }^{2}$

A systematic and detailed search for relevant studies was performed using the PubMed and Scopus databases. The following keywords and medical terms were used: "fear and cataract surgery", "fear and phacoemulsification", "anxiety and cataract surgery", "anxiety and phacoemulsification", "emotional factors and cataract surgery", "sedation and cataract surgery", "Sedation and phacoemulsification", "visual sensations during cataract surgery", "visual sensations during phacoemulsification", "first eye versus second eye cataract surgery", "music during cataract surgery", "massage and cataract surgery", "preoperative teaching of patients with cataract ", " preoperative teaching and cataract surgery ", "Preoperative education and cataract surgery", "preoperative counseling and cataract surgery", "cataract surgery and consent", "nursing intervention and cataract surgery".

\section{Inclusion and Exclusion Criteria}

The abstracts of the found articles were assessed for relevance, and references were screened to identify those that needed to be manually searched. Publications that were available only as abstracts or conference posters were excluded. In this way, 72 full-text original, review and case reports articles related to the topic were selected. None of the relevant articles were excluded based on language. Full-text translation was performed if necessary.

\section{Risk of Bias Assessment}

The methodological quality of included studies was evaluated independently by two authors (IO, JK).

\section{Data Extraction}

The studies' demographic details, participant characteristics, interventions, outcomes and limitations were independently extracted by two authors (IO, JK). If disagreements occurred, was discussed and resolved through discussion.

\section{Results}

\section{Fear and Anxiety and Its Influence on the Patient's Physiological State}

Fear is defined as an unpleasant emotional state triggered by the perception of threatening stimuli. Fear should be distinguished from anxiety, which is defined as an uncomfortable feeling of nervousness or worry about something that is happening or might happen in the future. These emotions differ from one important aspect. Fear has its cause, and once that cause is eliminated, the fear will subside. Anxiety is irrational in nature and is triggered by irrational thoughts. Anxiety is less clearly related to known events or stimuli. However, it creates a lot of tension and a sense of danger. ${ }^{3}$ In the categorical concept, anxiety can be a transient emotional state (state anxiety) or a persistent, permanent personality trait expressed as a readiness to react with anxiety in certain situations (trait anxiety).

Surgery is a strong stressor that can trigger physiological reactions such as tachycardia, hypertension, hyperventilation, hyperthermia, muscle tension, sweating, and psychological reactions such as fear, anxiety, and acute panic attacks. These physiological and psychological reactions are closely related and are usually undesirable. They can lead to an increase in intraocular pressure and/or blood pressure during surgery, as well as increase the risk of intraoperative bleeding, which may complicate the procedure. There are reports that preoperative anxiety and cardiovascular medical history in combination with prolonged ultrasound during cataract phacoemulsification are significantly more often associated with intraoperative complications. ${ }^{4}$ It is also known that people who experience greater emotional tension before the operation experience stronger pain sensations. Moreover, preoperative anxiety level was found to be the only significant predictor of pain during cataract surgery. ${ }^{5}$ 


\section{Fear and Anxiety Associated with Cataract Surgery}

\section{Frequency and Causes}

Fear and anxiety are the dominant and most frequently reported negative feelings related to cataract surgery. ${ }^{5-13}$ However, it is difficult to estimate the number of patients who experience them. Data vary depending on the study group, ophthalmic center, and phase of the entire procedure analyses were carried out. Older studies indicate that $33 \%$ of patients report their fear and $32 \%$ experience increased emotional tension prior to first-eye cataract surgery. ${ }^{7}$ The main cause of these emotions is the fear of surgery, such as the fear that the procedure will be painful, fear of failure, and possible deterioration or loss of vision. Patients often feel fear of moving their head or eye during surgery, coughing, or not being able to cooperate with the surgeon. ${ }^{13}$ The most common cause of fear and anxiety is the negative outcome that will result in the loss of vision (54-55\%), followed by pain during operation (41\%), its outcome (36\%), and finally the fear of the operation itself (29-33\%). ${ }^{9} 14$ As much as $12.7 \%$ of patients experience a fear of death during surgery. ${ }^{9}$ The fear of death occurs regardless of whether the patient undergoes major or minor surgery. ${ }^{10}$ It is also believed that in ophthalmic surgery, the fear of being blind is analogous to the fear of death associated with major surgery.

\section{Visual Sensations During Cataract Surgery as Fear Triggers}

Recent research has shown that most patients experience a variety of visual sensations during cataract surgery under local anaesthesia. The wide range of subjective visual feelings includes light perceptions, flashes, different colours, changes in brightness of the light, different shapes such as clouds, patches or circles, movements of instruments, movements of the surgeon's hands or fingers, and movements of water. ${ }^{15-17}$

These findings are clinically significant because some patients who undergo cataract surgery are frightened by intraoperative visual sensations. The number of patients who negatively evaluate visual impressions during cataract surgery depends on the type of anaesthesia used. Operations under retrobulbar anaesthesia result in 7.1 to $9.3 \%$ of patients being frightened ${ }^{18,19}$ and 3 to $13.5 \%$ when sub-Tenon's block is used. ${ }^{20,21}$ In the case of topical anaesthesia, the percentage is the largest, ranging from $15.4 \%$ to $26.4 \% .{ }^{15-17}$ Topical anaesthesia does not affect the function of the optic nerve, which is completely preserved; therefore, patients can experience a wide variety of visual experiences. In contrast, other forms of local anaesthesia may block nerve impulse conduction through the optic nerve, potentially reducing its function and the experience of colourful phenomena. Despite this deeper level of ocular anaesthesia, patients may still experience various visual effects during cataract surgery. Sedatives administered before or during surgery reduce the visual sensation.

In a study by Chaudhry et al, ${ }^{15}$ a high percentage (26.4\%) of fear due to intraoperative visual feelings resulted from the fact that patients were not informed about the possibility of such sensations prior to cataract surgery. A large percentage of ophthalmologists do not have adequate knowledge about the visual sensation during cataract surgery and the frightening feelings they cause in patients. ${ }^{22}$ As much as $54 \%$ of the United Kingdom (UK) ophthalmic surgeons believe that cataract surgery patients do not experience any visual experience. ${ }^{23}$ On the other hand, about half of Pakistani ophthalmologists believe that the visual impressions experienced by patients during surgery do not cause negative feelings in operated patients. ${ }^{22}$ This means that most surgeons do not pay attention to this aspect during the preoperative counselling of their patients. However, studies indicate that detailed discussion about visual sensations during cataract surgery during preoperative consultation helps to reduce the anxiety associated with it. ${ }^{24}$ Haripriya et $\mathrm{al}^{25}$ found a reduction in the percentage of patients experiencing anxiety from $12 \%$ to $4.5 \%$ after preoperative counselling on intraoperative visual phenomena.

Summary of the date on visual sensations during cataract surgery as fear triggers are shown in Table 1.

\section{Fasting versus Anxiety}

Whether a patient operated for cataracts, especially under topical anaesthesia, should be on an empty stomach before the procedure is still an ongoing issue. The rigid recommendation to abstain prior to cataract surgery is used in ophthalmic centres in many countries, although there is considerable evidence of adverse effects of this practice. ${ }^{26}$ Fasting has been found to cause a number of undesirable emotions in patients, including anxiety, irritability, and anger, often accompanied by headaches. ${ }^{27,28}$ Other negative effects of abstaining include dehydration, hypovolemia, hypotension, catabolism, and insulin resistance. On the other hand, fasting before surgery under local anaesthesia provides the possibility of conversion to general 
Table I Visual Sensations During Cataract Surgery as Fear Triggers

\begin{tabular}{|l|c|c|c|l|}
\hline Author & Year & $\begin{array}{c}\text { Sample } \\
\text { Size }\end{array}$ & Setting & Main Findings \\
\hline Chaudhry et al $^{15}$ & 2014 & 53 & Pakistan & $\begin{array}{l}26.4 \% \text { of patients operated on cataract under topical anesthesia reported fear due to } \\
\text { intraoperative visual sensations }\end{array}$ \\
\hline Ang et al ${ }^{16}$ & 2007 & 98 & Singapore & $\begin{array}{l}19.4 \% \text { of operated due to cataract under topical anesthesia found their visual experience } \\
\text { frightening }\end{array}$ \\
\hline Au Eong et al ${ }^{17}$ & 2000 & 52 & Singapore & $15.4 \%$ of patients operated under topical anesthesia found their visual experience frightening \\
\hline Au Eong et al ${ }^{18}$ & 2000 & 52 & Singapore & $\begin{array}{l}7.1 \% \text { of patients operated under retrobulbar anesthesia found their visual experience } \\
\text { frightening }\end{array}$ \\
\hline Rengaraj et al ${ }^{19}$ & 2004 & 306 & India & $\begin{array}{l}10.4 \% \text { in the topical anesthesia group and } 9.3 \% \text { in the retrobulbar anesthesia group found } \\
\text { their visual experience frightening }\end{array}$ \\
\hline Prasad et al ${ }^{20}$ & 2003 & 121 & $\begin{array}{l}\text { United } \\
\text { Kingdom }\end{array}$ & $\begin{array}{l}3 \% \text { of patients during phacoemulsification cataract surgery under sub-Tenon's block found } \\
\text { the visual experience frightening and } 4 \% \text { thought it to be unpleasant }\end{array}$ \\
\hline $\begin{array}{l}\text { Wickremasinghe } \\
\text { et al }{ }^{21}\end{array}$ & 2003 & 104 & $\begin{array}{c}\text { United } \\
\text { Kingdom }\end{array}$ & $\begin{array}{l}13.5 \% \text { of patients operated under subtenons anesthesia found the visual experience } \\
\text { frightening. Frightening visual experiences were significantly associated with the perception } \\
\text { of colour (P=0.005) and photophobia (P=0.003). }\end{array}$ \\
\hline
\end{tabular}

anaesthesia or airway manipulation in a critical situation. It also minimises aspiration risk when patients require intravenous sedation. This is especially true for the elderly with disorders such as gastroesophageal reflux, hiatus hernia, diabetic neuropathy, or renal dysfunction. ${ }^{26}$

Considering all the pros and cons, the prevailing view today is that the advantages of abstaining before routine cataract surgery under local anaesthesia are an outbalance of the low risk of pulmonary complications. This applies mainly to patients who are not sedated. ${ }^{29}$ In UK, patients under local anaesthesia without sedation do not need to be fasted. $^{27}$

\section{Factors Related to Fear and Anxiety in Patients Undergoing Cataract Surgery}

A higher level of fear and anxiety is found in women, hypochondriacs, hysterics, and trait anxiety. 6,11 People with higher visual acuity before surgery are more anxious about losing their vision. On the other hand, older people with poor visual acuity are less stressed in this respect. ${ }^{7}$

Additional aspects also influence the emotional condition of the patients. These include the relationship between the patient and the doctor, the scope of the patient's preoperative education about cataract and its treatment, previous experience, waiting period before the surgery, work organisation in the hospital in which the operation takes place, social support, the patient's general emotional state, and coping with stress. ${ }^{12}$ The emotional state of a patient depends on many unpredictable circumstances and varies from stage to stage throughout the cataract treatment process.

\section{Intensity of Fear and Anxiety in the Perioperative Period}

The intensity of fear and anxiety associated with the cataract removal procedure fluctuated continuously during the perioperative period. At the preoperative stage, patients experience strong negative emotions, gradually increasing until the day of the operation, when they reach their maximum. Fear builds up on the admission day and in the immediate preoperative stage. Anxiety clearly decreases immediately after the operation because of the relief that the procedure is over. ${ }^{8,11}$ The next day, the tension increases again, but it is usually not as high as before the surgery. This rebound in emotions results from the fear of surgical outcomes. ${ }^{12}$ Below is an analysis of the individual stages of the routine cataract surgery procedure, taking into account the causes of fear and anxiety typically occurring during these periods.

\section{Diagnosis}

The first step in the entire cataract treatment procedure is to make a diagnosis and advise the patient to undergo surgery. This information can create anxiety and uncertainty in patients due to the uncertainty associated with surgery outcomes. Studies have shown that some people 
feel more anxious at the time of diagnosis than on the day of the procedure. ${ }^{8}$ Usually, tension decreases when the patient obtains more information about the course of the entire cataract treatment process, including the surgery itself and its expected effects.

\section{Waiting Time for a Cataract Surgery}

The waiting time for cataract surgery varies from country to country. The longer it is, the greater is the negative impact on the patient's emotional state. Poor visual acuity in patients with cataracts may significantly limit their daily activities. Marback et $\mathrm{al}^{9}$ reported that due to the deterioration of visual acuity as a result of the development of cataracts, up to $83 \%$ of patients have difficulties in performing everyday activities, such as walking, watching $\mathrm{TV}$, reading, or doing needlework. The development of cataracts and the accompanying limitations in everyday life cause anxiety in $26 \%$ of the above-mentioned subjects, sadness in $25 \%$, and anger for needing to undergo surgery in $4.5 \%$. In addition, there is a fear of further deterioration of visual acuity in the face of long waiting times for surgery. If the patient is assisted with daily activities, then anxiety and fear are reduced.

Experience with first-eye surgery also affects fear and anxiety levels. When these experiences are positive, the tension before the operation of the other eye is much lower. ${ }^{12}$ Support from family, neighbours, or friends may have different influences on the emotions of the operated person. Positive and even more negative experiences and opinions of other people about cataract surgery strongly affect the emotions of the patient preparing for the procedure. They can both weaken and increase fear of surgery. In this situation, it is extremely important to be able to separate the subjective feelings of other people from the reliable medical knowledge provided by a doctor.

\section{Day of Surgery}

The day of surgery was the most stressful. During this time, the fear of pain and surgery as such and the possibility of negative outcomes were the strongest. Trust in the surgeon is an important factor in reducing fear. If the surgeon is experienced and recommended, preoperative anxiety is significantly reduced. If a patient learns that the operation will be performed by a trainee, the feeling of fear increases drastically. ${ }^{30}$ Most patients feel more comfortable during surgery when among the staff there is someone they know. Being one of many anonymous people operated on a given day worsens the patient's well- being. ${ }^{12}$ Patients who establish even a temporary relationship and sympathy with fellow patients feel less stress while waiting for a moment to go to the operating theatre.

The time spent in the operating room is particularly stressful due to the place, which is sterile by definition, and therefore less cosy and patient-friendly. The lying position, covering the body and head with surgical drapes, cold air conditioning, extraneous noises of working medical devices, and the bustle of the staff are stressful. ${ }^{13}$ In people who have already been operated on one eye, additional stress during surgery occurs when the activities and procedures performed by medical personnel differ from those remembered from the previous operation. The patient interpreted this as an appearance of intraoperative difficulties. It turns out that a great many patients perceive differences, if any, in the various elements of the management of the operating theatre during the first and second eye surgeries. During the second procedure, they are usually less anxious, and therefore their perception increases. $^{31,32}$ This should be considered if the operation of the second eye differs from the first. This may apply to procedures performed in different ophthalmic centres, where perioperative procedures may be slightly different. But also the same ophthalmic centre, when the operated eyes differ in the scale of the difficulty of the procedure and require a different intraoperative approach, or when the time interval between operations is large enough that certain procedures could be modified. The calm voice of the surgeon has a very positive effect on calming the patient during the operation, explaining that the operation is as planned, nothing wrong is happening, and the procedure will end soon. ${ }^{13,33}$

\section{Early Period After Cataract Surgery}

On the day of the immediate postoperative visit, the patient still felt tension, but it was much lower than before the surgery and was caused by the fear of outcome. When visual acuity after surgery is not improved, there is a growing concern that the surgery has failed and that vision will be lost. Conversation with a doctor about the causes of reduced visual acuity can reduce patients' anxiety. ${ }^{12}$ Anxiety about the proper course of eye healing increases in a patient with poor postoperative visual acuity, especially if the waiting period between follow-up visits is long. The possibility of more frequent check-ups and consulting patients' doubts with a doctor significantly reduces the tension that accompanies the patient during this period. 
Interestingly, in the postoperative period, patients usually experience reduced anxiety before surgery. When asked about the most stressful feeling related to the entire procedure before and again after the cataract operation, patients gave different reasons. Before the surgery, there was a fear of vision loss, and after the operation, the greatest anxiety was related to the surgery itself. ${ }^{10}$ In the postoperative period, when the patient experienced an improvement in visual acuity, the related tension decreased significantly. The fear felt before surgery is interpreted as a natural fear accompanying the procedure itself.

\section{Late Period After Cataract Surgery}

The late period after cataract surgery creates the least stressful situation. If the eye takes a long time to heal, the fear returns whether visual acuity will eventually improve. Patients with postoperative complications experience a fear of loss of vision and further treatment, including surgery. The long waiting time for the operation of the second eye also causes anxiety, and the associated fear that surgery performed later rather than sooner will have a negative outcome.

\section{Comparison Between Fear and Anxiety Feelings During First- and Second-Eye Surgery}

Fagerström ${ }^{7}$ found that the positive experiences of the first eye surgery, including its painless course and satisfactory improvement in vision, significantly reduced the fear of the second surgery and the fear of becoming blind. Pager ${ }^{34}$ noted that patients who had operated the second eye were less anxious prior to surgery and rated the second surgery as more comfortable than the first one, and outcome satisfaction more often met their preoperative expectations. Even $2 / 3$ of patients who were "very or extremely anxious" during the first operation did not experience anxiety during the second eye surgery. ${ }^{31}$ Interestingly, although most of the patients were less nervous before the second surgery, they considered the second eye surgery more painful and longer than the first one. ${ }^{35,36}$ This is due to the drop in tension before the second operation, which makes the patient more aware and focused.

Mitsonis et $\mathrm{al}^{6}$ showed that during the first-eye surgery, patients experienced the greatest peak anxiety on the day of the surgery, while those operated on the second eye presented no fluctuations in rated anxiety. In the preoperative period, anxiety is higher in patients operated for the first time, and in the postoperative period in those operated for the second time. ${ }^{8,11}$ A comparison of the causes of negative emotions in patients operated on in both eyes showed that the fear of being blinded and the operation as such prevailed before the first operation, and in those operated on the cataract of the other eye, the fear of intraoperative complications and lack of vision improvement. ${ }^{10}$

Most reports indicate that fear and tension are lower before the second eye cataract surgery. However, patients experience greater stress before the second surgery. In this case, less negative emotions before the first eye surgery result from little knowledge about the surgery itself and its course, and the lack of interest in possible outcomes. The experience from the first operation increases the tension while waiting for the second operation. ${ }^{12}$

Summary of the date on comparison of patients' feelings during first- or second-eye cataract surgery are shown in Table 2.

\section{Discussion}

Simple methods, such as reducing noise, maintaining a pleasant temperature in the rooms, reducing lighting, or using a calm tone of voice by medical staff can improve the patient's comfort and thus reduce anxiety during cataract surgery. There is also evidence of the beneficial effects of other methods of reducing fear and anxiety, both before and during surgery.

\section{Pharmacological Methods}

Similar to every procedure, cataract surgery also induces fear and anxiety. Apart from traditional anaesthesia of the eye, sedation and/or analgesia are sometimes used to minimise the patient's emotional discomfort. There is no gold standard for the management of anaesthesia, and the use of sedation/analgesia varies widely between countries. It is dictated by many factors, including resources, healthcare system policy, institutional practice, tradition, patient expectations, and preferences of ophthalmologists and anesthesiologists. There are countries where sedation appears to be routinely used for cataract surgery, such as Singapore, ${ }^{27}$ the USA, ${ }^{37}$ and Canada. ${ }^{38}$ There are also countries where the frequency of sedation is negligible, such as in the UK $(4 \%)^{39}$ or absent, such as in the Netherlands. ${ }^{27}$ There is a long tradition in the UK in which nurses prepare patients for cataract surgery. Their task is to explain to the patient the basics of the entire procedure inform about the recommended behaviour in the operating theatre, calm patient down, and clarify all doubts. This brings very good results in terms of reducing 
Table 2 Comparison Between Patients` Feelings During First- or Second-Eye Cataract Surgery

\begin{tabular}{|c|c|c|c|c|}
\hline Author & Year & $\begin{array}{l}\text { Sample } \\
\text { Size }\end{array}$ & Setting & Main Findings \\
\hline Mitsonis et $\mathrm{al}^{6}$ & 2006 & 278 & Greece & $\begin{array}{l}\text { During the first-eye surgery, patients experienced the greatest peak anxiety on the day of } \\
\text { the surgery, while those operated on the second eye presented no fluctuations in rated } \\
\text { anxiety }\end{array}$ \\
\hline Fagerström et $\mathrm{al}^{7}$ & 1993 & 100 & Finland & $\begin{array}{l}\text { Positive experiences of the first-eye surgery, including its painless course and satisfactory } \\
\text { improvement in vision, significantly reduced the fear of the second surgery and the fear of } \\
\text { becoming blind }\end{array}$ \\
\hline Foggitt et $\mathrm{al}^{8}$ & 2001 & 108 & $\begin{array}{l}\text { United } \\
\text { Kingdom }\end{array}$ & $\begin{array}{l}\text { In the preoperative period, anxiety is higher in patients operated for the first time, and in } \\
\text { the postoperative period in those operated for the second eye }\end{array}$ \\
\hline Ramirez et a $\left.\right|^{10}$ & 2017 & 61 & USA & $\begin{array}{l}\text { Fear of being blinded and the operation as such prevailed before the first eye cataract } \\
\text { surgery. In those operated on the second eye prevailed fear of intraoperative complications } \\
\text { and lack of vision improvement. }\end{array}$ \\
\hline Heard et $\mathrm{al}^{31}$ & 2020 & 198 & USA & $\begin{array}{l}2 / 3 \text { of patients who were "very or extremely anxious" during the first operation did not } \\
\text { experience anxiety during the second-eye surgery }\end{array}$ \\
\hline Ługowska et $\mathrm{al}^{32}$ & 2020 & 200 & Poland & $\begin{array}{l}\text { Patients experienced greater anxiety before their first-cataract surgery than before } \\
\text { the second-eye surgery }\end{array}$ \\
\hline Pager et $\mathrm{al}^{34}$ & 2005 & 160 & Wales & $\begin{array}{l}\text { Patients who had operated the second eye were less anxious prior to surgery and rated } \\
\text { the second surgery as more comfortable than the first one }\end{array}$ \\
\hline Yu et al ${ }^{35}$ & 2016 & 127 & China & $\begin{array}{l}\text { Patients experienced less anxiety, a greater number of eye bulges and pain during second } \\
\text { cataract surgery compared to the first surgery }\end{array}$ \\
\hline Adatia et $\mathrm{al}^{36}$ & 2015 & 292 & Canada & $\begin{array}{l}42.8 \% \text { patients rated second-eye surgery as more unpleasant procedure. } 72 \% \text { were similarly } \\
\text { or more relaxed during the second operation. The second-eye cataract surgery was } \\
\text { perceived as being a longer and more painful by } 45.4 \% \text { of patients }\end{array}$ \\
\hline
\end{tabular}

anxiety and improving patient cooperation during surgery. ${ }^{40,41}$ Many of the operated patients seemed happy with an explanation rather than sedation. It must be remembered that sedation, although it reduces anxiety, reduces the patient's ability to cooperate during the operation. This is especially true for the elderly, who constitute the majority of cataract surgeries.

Regardless of the general approach to sedation, there is always a certain group of patients whose fear of surgery and emotions associated with it are so great that without pharmacological sedation surgery cannot be performed. It is believed that ideal sedation during cataract surgery should reduce anxiety and stress response, raise the pain threshold, improve cooperation, and eliminate unwanted movements. ${ }^{27}$ Sedation should strike a balance between the reduction of anxiety and pain control without losing consciousness and awareness. Sedative and analgesic medications should not disturb the patient's ability to communicate. There are currently two sedation options for cataract surgery: oral administration before surgery or intravenous administration during surgery.
Oral sedatives include benzodiazepines (diazepam, midazolam, and lorazepam), gabapentinoids (pregabalin, gabapentin), melatonin, and $\alpha 2$ adrenoreceptor agonists (clonidine). Preoperative oral medication has the disadvantage that the effect is delayed in time, and it is impossible to predict precisely when it occurs. There is also no exact control of sedation level. ${ }^{27}$ There are reports that intravenous midazolam administered $15 \mathrm{~min}$ before cataract surgery does not significantly reduce pain and anxiety levels. $^{42}$

When administered intravenously, the following drugs are used: benzodiazepines, propofol, opioids, and an $\alpha 2$ adrenoreceptor agonist. Estimating the appropriate dose of a drug to achieve the desired level of sedation with minimal side effects is difficult because the spectrum of patient response to a given drug is very broad. ${ }^{27}$ Hence, with a very short procedure, that is, cataract phacoemulsification, the gains in the form of calming the patient may not outweigh the losses caused by the deterioration of his ability to cooperate. The patient's reaction to intravenous 
sedatives is impossible to predict. Some elderly people go into a deeper level of sedation and even fall asleep. The patient may move uncontrollably when confusion occurs after a sudden wake up.

Melatonin is an alternative to the common sedatives used in anaesthesia. Studies on the effects of melatonin showed that it reduces anxiety, enhances analgesia, and reduces intraocular pressure when administered orally at a dose of 3 or $10 \mathrm{mg} 60-90$ minutes before surgery. ${ }^{43,44}$ The sedative effect of melatonin is explained by its effect on GABAergic and benzodiazepine receptors. Melatonin does not affect psychomotor skills, and thus the patient's ability to cooperate.

As suggested by Nijkamp et al, ${ }^{11}$ complete suppression of the fear of surgery using pharmacological methods is not beneficial because low levels of anxiety are actually recommended and may be helpful in effective preparation for surgery and proper coping with discomfort during the procedure. It also prevents disappointment and failure of patients' expectations of postoperative outcomes. In summary, the modern technique of cataract surgery, including small-incision phacoemulsification under topical anaesthesia, is a very short and safe medical procedure associated with minimal pain. Adequate education before surgery is usually sufficient to reduce the stress associated with surgery.

\section{Preoperative Educating and Counselling}

Preoperative education and counselling, the aim of which is to provide the patient with reliable and accessible information on cataracts and methods of its treatment, has a huge positive impact on reducing the fear and anxiety associated with surgery. ${ }^{45}$ Ophthalmologists and other healthcare professionals can contribute to improving communication with patients in the preoperative period. These can be nurses, social workers, psychologists, health care educators, teachers, and occupational therapists. ${ }^{9}$ The aim of preoperative education and counselling is not only to provide information and clarify the patient's doubts, but also to reassure them. To meet this task, the person interviewing the patient must be properly prepared for it, both in terms of content and psychology.

A well-conducted preoperative information session should consider patient needs and the specificity of their age. Sufficient time should be devoted and allow them to asking questions. The type of information that is given and the way it is communicated are also important. People who are more knowledgeable about the procedure and those who accept the proposed treatments are usually less stressed. To increase the acceptance of patients for the proposed procedures, it must make sense to them. However, the amount of information required by each patient depends on the individual. There are people who do not want to be thoroughly informed, especially regarding possible complications. Thus, a statement can be made that as medical information increases, so does fear and anxiety. ${ }^{46-49}$ This applies more often to elderly and poorly educated individuals. While it is important for the patient to understand the risks involved, balancing the patient's anxiety and likelihood of complications is a very delicate matter. Excessive informing with possible complications can be counterproductive. ${ }^{10}$ During the conversation with the patient, emphasis should be placed on what he or she will feel, see, or hear during the operation, and to a lesser extent on the details of the surgical technique itself.

Some patients expect to be told almost everything about the surgery and they appreciate the doctor's honesty, especially about all possible complications. This allows them to make a fully informed decision regarding consent to surgery. ${ }^{12}$ This advantage is especially emphasised by people who cope well in stressful situations.

The way in which medical information is communicated to the patient is important. Older people prefer traditional methods, while younger patients are eager to use multimedia aids. Most operated patients prefer oral consultations rather than written information. Direct contact with a doctor brings more positive effects, allowing the patient to ask questions and clarify incomprehensible issues on a regular basis. On the other hand, the advantage of written information is the possibility of repeated access to it and recalling information that has not been remembered. The research also shows that the combination of face-to-face discussion with the information brochure is best rated by operated patients. This provides a high and desirable level of information retention in patients. ${ }^{12}$

The use of multimedia in the process of educating patients increases the number of information remembered by the patient and positively influences the emotional state. Computer-animated videos are one of the most frequently used multimedia methods. Tan et al ${ }^{50}$ showed that watching simple videos significantly reduced fear. In his research, $54 \%$ of subjects preferred verbal (spoken) information, $47 \%$ preferred video $\mathrm{CD}$ information, and $36 \%$ preferred printed information. Interesting observations were made by Pager et al, ${ }^{34}$ who presented two videos to the respondents before the procedure: one about the 
formation of cataracts and the other about the course of the operation itself and possible complications. Although it was shown that people who watched pre-recorded surgery were more nervous than those who watched the film only containing the formation of lens opacities, the final satisfaction with the surgery was higher in the former. In addition, their intraoperative well-being was much better, and their pain and discomfort were much lower than expected. $^{51-53}$

One idea for reducing the fear of cataract surgery is to involve nurses or social workers in the patient education process. It is about people who easily establish contact and good relations with the patient, which facilitates communication and inspires trust. It has been shown that informative, educational, and planned nursing care has a very beneficial effect on reducing the level of anxiety in patients undergoing cataract surgery. ${ }^{54}$ Gong et $\mathrm{al}^{40}$ showed that nursing intervention, in the form of several meetings in the week immediately preceding admission to the hospital, significantly reduced preoperative anxiety, improved cooperation between the patient and medical staff during surgery, and increased satisfaction with postoperative outcomes. These meetings included psychological support for the patient, helped in preparing for the procedure, and provided the necessary information on the structure of the eye, cataracts and its treatment, as well as on pain management and postoperative rehabilitation. The authors indicate that the involvement of nurses in the process of preparing patients for surgery should be a routine procedure.

The great fear of cataract surgery may be the reason for cancelling the procedure. The importance of preoperative counselling in preventing patients from withdrawing from surgery was shown in the research by Newman-Casey et al. ${ }^{55}$ According to their study, adequate education increases the number of people who decided to undergo surgery by $14 \%$ despite prior fears and the willingness to postpone it indefinitely. As much as $98.9 \%$ of the respondents were satisfied or very satisfied with their counselling. $93 \%$ of subjects said that counsellors had a decisive influence on their decision to undergo cataract surgery.

\section{Hand Massage Before Cataract Surgery}

Hand massage therapy is one of the most popular methods for reducing nervous tension and relaxing the patient. It is safe, inexpensive, non-invasive, and easy to apply. One of the proven massage methods to reduce preoperative anxiety is slow-stroke back massage (SSBM). During SSBM, the hands side over the skin which causes gentle movement of the skin but not the deep muscles. SSBM massage was performed $30 \mathrm{~min}$ before the procedure in a sitting position. The massage is slow, rhythmic, and involves gentle movements of the hands on a patient's back, with a speed of about 60 moves per minute. ${ }^{56}$ It was shown that massaged people were more relaxed and less nervous about the operation, and their anxiety level was statistically significantly lower after the massage than before. ${ }^{56,57}$

A short 5-10 min manual massage, performed immediately before cataract surgery, not only lowers the anxiety level, ${ }^{58,59}$ but also has a positive effect on other vital parameters, the increase of which may be a symptom of nervousness and nervousness tension accompanying the patient before surgery. Massage has a beneficial effect on reducing heart rate, systolic and diastolic blood pressure, and respiration rate. ${ }^{60,61}$ It did not have any effect on oxygen saturation.

Although the exact mechanism by which massage reduces anxiety is unknown, it is believed that it may reduce and weaken patients ' perception and environmental sensitivity. In addition, it has a stimulating and relaxing effect on muscles and tissues by improving blood flow. Another hypothesis is that massage increases the activity of the parasympathetic nervous system, inhibits the sympathetic nervous system, and reduces cortisol levels. The production of endorphins, including serotonin and dopamine, is stimulated, which reduces anxiety levels. ${ }^{62}$

\section{Music Used for the Cataract Surgery}

Many studies have shown that listening to music before and during cataract surgery has a positive effect on patients. Music listened to immediately before surgery lowers the level of anxiety and fear ${ }^{63-68}$ and reduces anxiety-related hypertension during surgery. ${ }^{63}$ Listening to music during surgery reduces pain sensations, ${ }^{69}$ anxiety level, ${ }^{64,67,70}$ and overall blood pressure, heart rate, respiratory rate, and decrease the need for sedative drugs. ${ }^{64,68,70}$

Physiological and emotional reactions to music depend on many factors, such as musical preferences or current mood. However, there are universal mechanisms for perceiving music. Acoustic driving is a natural phenomenon related to the influence of music on the listener from a physiological point of view. It is based on the adaptation of the rhythm of the recipient's body physiological processes to the rhythm of the music being listened to by resonance. The heartbeat, breathing, 
and conduction of nerve impulses can be synchronised with the rhythm of the music. This is due to the influence of music on the autonomic nervous system and related organs. The autonomic nervous system is responsible for the level of activation of the body, which translates into heart rate, pace and depth of breathing, blood pressure, muscle tension, secretion of hormones and neurotransmitters, rate of nerve impulse conduction, the immune system, and other physiological processes. Emotional and physiological relaxation is achieved with the help of appropriately selected music, which inhibits the excessive activity of the sympathetic system and stimulates the parasympathetic system. The activation of the parasympathetic system is associated with slowing down the heart and breathing, lowering blood pressure, and reducing muscle tension. Music can also inhibit the secretion of hormones and neurotransmitters in the body, including cortisol and adrenaline, which are responsible for the mobilisation of the organism and negative affective states. However, it increases the secretion of chemicals related to good mood and physical well-being, such as dopamine, serotonin, and endogenous opioids. ${ }^{71}$

Some studies have shown that music selected by patients can be useful in reducing stress levels, even when it is not typically sedative. Patients who listened to music during cataract surgery experienced less intraoperative anxiety if they heard no music or music they had selected themselves as opposed to music selected by the operating surgeon. ${ }^{72}$ Older people who operated on for cataracts under retrobulbar anaesthesia were more satisfied when they listened to relaxing music during surgery and when they had a choice whether to listen to music during surgery or not. ${ }^{73}$

Summary of the date on the effect of listening to music before and during cataract surgery are shown in Table 3 .

Table 3 Music Listened Before and During Cataract Surgery

\begin{tabular}{|c|c|c|c|c|}
\hline Author & Year & $\begin{array}{l}\text { Sample } \\
\text { Size }\end{array}$ & Setting & Main Findings \\
\hline Guerrier et $\mathrm{al}^{63}$ & 2020 & 310 & France & $\begin{array}{l}\text { Music listened to immediately before cataract surgery lowers the level of anxiety and } \\
\text { reduces anxiety-related hypertension during surgery }\end{array}$ \\
\hline Merakou et al ${ }^{64}$ & 2015 & 200 & Greece & $\begin{array}{l}\text { Music listened to before surgery lowers the level of anxiety and fear. Listening to music } \\
\text { during surgery reduces anxiety level and overall blood pressure }\end{array}$ \\
\hline Bringman et $\mathrm{al}^{65}$ & 2009 & 177 & Sweden & $\begin{array}{l}\text { Relaxing music decreases the level of anxiety in a pre-operative setting to a greater extent } \\
\text { than orally administrated midazolam }\end{array}$ \\
\hline Bellan et $\mathrm{al}^{66}$ & 2002 & 144 & Canada & $\begin{array}{l}\text { Oral sedation and listening to music before surgery were associated with decreased anxiety } \\
\text { and increased levels of sedation }\end{array}$ \\
\hline Muddanaet al ${ }^{67}$ & 2020 & 165 & India & $\begin{array}{l}\text { Music listened before and during cataract surgery presented reductions in self-reported } \\
\text { anxiety before, during and after surgery and a significant decrease in postoperative blood } \\
\text { pressure }\end{array}$ \\
\hline $\begin{array}{l}\text { Wiwatwongwana } \\
\text { et al }{ }^{68}\end{array}$ & 2016 & $14 \mid$ & Thailand & $\begin{array}{l}\text { Intraoperative music was proven to decrease anxiety level and lower systolic blood } \\
\text { pressure }\end{array}$ \\
\hline Choi et al ${ }^{69}$ & 2018 & 52 & $\begin{array}{l}\text { Republic } \\
\text { of Korea }\end{array}$ & $\begin{array}{l}\text { Korean traditional music had a significant effect on reducing pain experienced by patients } \\
\text { during cataract surgery }\end{array}$ \\
\hline Camera et $\mathrm{al}^{70}$ & 2008 & 203 & $\begin{array}{l}\text { Hawaii, } \\
\text { USA }\end{array}$ & $\begin{array}{l}\text { Live classical piano music lowered the blood pressure, heart rate, and respiratory rate in } \\
\text { patients undergoing ophthalmic surgery }\end{array}$ \\
\hline Karwoski et $\mathrm{al}^{72}$ & 2010 & 93 & USA & $\begin{array}{l}\text { Patients having cataract surgery experienced less intra- and postoperative anxiety if they } \\
\text { heard no music or music they had selected themselves as opposed to music selected by the } \\
\text { operating surgeon }\end{array}$ \\
\hline Cruise et $\mathrm{al}^{73}$ & 1997 & 120 & Canada & $\begin{array}{l}\text { Elderly patients undergoing cataract surgery under retrobulbar block were more satisfied i } \\
\text { they heard relaxing music, rather than relaxing suggestions or white noise. The type of } \\
\text { auditory stimuli did not influence the level of anxiety. }\end{array}$ \\
\hline
\end{tabular}




\section{Conclusion}

Cataract surgery under local anaesthesia is often accompanied by fear and anxiety. These emotions result from fear of surgery, such as pain and loss of vision. Abstaining before surgery is a factor that increases preoperative anxiety, and visual sensations during cataract surgery increase fear. Women, hysterics, and hypochondriacs showed higher levels of state anxiety. The greatest intensity of negative emotions occurred on the day of the cataract surgery. Patients operated on both eyes experienced less fear and anxiety before the operation of the other eye. The most effective in reducing fear and tension is adequate preoperative education and counselling for patients. Patients prefer oral information rather than being printed. Combining a conversation with watching a video of cataract surgery significantly lowers preoperative anxiety. Short massage administered immediately before surgery has been shown to reduce anxiety, heart rate, systolic and diastolic blood pressure, and respiration rate. Music listened to by patients before and during surgery has a very beneficial effect on reducing fear and anxiety and reducing pain sensation and anxiety-related hypertension during surgery.

\section{Data Sharing Statement}

All materials and information are available upon an e-mail request on corresponding author.

\section{Funding}

This research did not receive any specific grant from funding agencies in the public, commercial, or not-forprofit sectors.

\section{Disclosure}

The authors declare no conflicts of interest in this work.

\section{References}

1. WHO. Cataract, priority eye diseases, prevention of blindness and visual impairment; 2021. Available from: http://www.who.int/blind ness/causes/priority/en/index1.html. Accessed July 2, 2018.

2. Page MJ, McKenzie JE, Bossuyt PM, et al. The PRISMA 2020 statement: an updated guideline for reporting systematic reviews. BMJ. 2021;372:n71. doi:10.1136/bmj.n71

3. Crooks R, Stein J. Psychology: Science, Behavior and Life. New York: Holt, Rinehart and Winston; 1988.

4. Pérez-Campagne E, Basdekidou C, Petropoulos I, Noachovitch B, Moubri M. Impact of preoperative and intraoperative factors in cataract surgery. Klin Monatsblätter Augenheilkd. 2013;230(4):326-329. doi:10.1055/s-0032-1328393
5. Socea SD, Abualhasan H, Magen O, et al. Preoperative anxiety levels and pain during cataract surgery. Curr Eye Res. 2019;45(4):471-476. doi:10.1080/02713683.2019.1666996

6. Mitsonis CI, Dimopoulos NP, Andriotis NM, et al. Anxiety and depression in cataract surgery: a pilot study in the elderly. Psychol Rep. 2006;99(1):257-265. doi:10.2466/pr0.99.1.257-265

7. Fagerström R. Fear of a cataract operation in aged persons. Psychol Rep. 1993;72(3 Suppl):1339-1346. doi:10.2466/pr0.1993.72.3c.1339

8. Foggitt PS. Anxiety in cataract surgery: pilot study. J Cataract Refract Surg. 2001;27(10):1651-1655. doi:10.1016/S0886-3350(01)00859-8

9. Marback R, Temporini E, Júnior NK. Emotional factors prior to cataract surgery. Clinics. 2007;62(4):433-438. doi:10.1590/S180759322007000400010

10. Ramirez DA, Brodie FL, Rose-Nussbaumer J, Ramanathan S. Anxiety in patients undergoing cataract surgery: a pre- and postoperative comparison. Clin Ophthalmol. 2017;11:1979-1986. doi:10.2147/OPTH.S146135

11. Nijkamp MD, Kenens CA, Dijker AJM, Ruiter RAC, Hiddema F, Nuijts RMMA. Determinants of surgery related anxiety in cataract patients. $\mathrm{Br} J$ Ophthalmol. 2004;88(10):1310-1314. doi:10.1136/ bjo.2003.037788

12. Nijkamp MD, Ruiter RAC, Roeling M, et al. Factors related to fear in patients undergoing cataract surgery: a qualitative study focusing on factors associated with fear and reassurance among patients who need to undergo cataract surgery. Patient Educ Couns. 2002;47 (3):265-272. doi:10.1016/S0738-3991(02)00002-2

13. Obuchowska I, Ługowska D, Mariak Z, Konopińska J. Subjective opinions of patients about step-by-step cataract surgery preparation. Clin Ophthalmol. 2021;15:713-721. doi:10.2147/OPTH.S298876

14. Oliveira RD, Temporini ER, José NK, Carricondo PC, José ACK. Perceptions of patients about cataract. Clinics. 2005;60(6):455-460. doi:10.1590/S1807-59322005000600005

15. Chaudhry TA, Aqil A, Aziz K, Javed AA, Tauqir MZ, Ahmad K. Patients' visual experience during phacoemulsification cataract surgery and associated fear. BMC Res Note. 2014;7:663. doi:10.1186/ 1756-0500-7-663

16. Ang CL, Eong KGA, Lee SSG, Chan SP, Tan CSH. Patients' expectation and experience of visual sensations during phacoemulsification under topical anaesthesia. Eye. 2006;21(9):1162-1167. doi:10.1038/sj.eye.6702427

17. Eong KGA, Low $\mathrm{CH}$, Heng WJ, et al. Subjective visual experience during phacoemulsification and intraocular lens implantation under topical anesthesia. Ophthalmology. 2000;107(2):248-250. doi:10.1016/S0161-6420(99)00080-9

18. Eong KGA, Lim TH, Lee HM, Yong VSH. Subjective visual experience during phacoemulsification and intraocular lens implantation using retrobulbar anesthesia. J Cataract Refract Surg. 2000;26 (6):842-846. doi:10.1016/S0886-3350(99)00452-6

19. Rengaraj V, Radhakrishnan M, Eong K-GA, et al. Visual experience during phacoemulsification under topical versus retrobulbar anesthesia: results of a prospective, randomized, controlled trial. Am J Ophthalmol. 2004;138(5):782-787. doi:10.1016/j.ajo.2004.06.023

20. Prasad N, Kumar CM, Patil BB, Dowd TC. Subjective visual experience during phacoemulsification cataract surgery under sub-Tenon's block. Eye. 2003;17(3):407-409. doi:10.1038/sj.eye.6700370

21. Wickremasinghe SS, Tranos PG, Sinclair N, Andreou PS, Harris ML, Little BC. Visual perception during phacoemulsification cataract surgery under subtenons anaesthesia. Eye. 2003;17(4):501-505 doi:10.1038/sj.eye.6700414

22. Tauqir MZ, Chaudhry TA, Mumtaz S, Ahmad K. Knowledge of patients' visual experience during cataract surgery: a survey of eye doctors in Karachi, Pakistan. BMC Ophthalmol. 2012;12:55. doi:10.1186/1471-2415-12-55

23. Laude A, Eong KGA, Mills KB. Knowledge of visual experience during cataract surgery under local anaesthesia: a nationwide survey of UK ophthalmologists. Br J Ophthalmol. 2006;93(4):510-512. doi:10.1136/bjo.2006.097030 
24. Voon LW, Eong KGA, Saw SM, Verma D, Laude A. Effect of preoperative counseling on patient fear from the visual experience during phacoemulsification under topical anesthesia: multicenter randomized clinical trial. $J$ Cataract Refract Surg. 2005;31 (10):1966-1969. doi:10.1016/j.jcrs.2005.03.059

25. Haripriya A, Tan CSH, Venkatesh R, Aravind S, Dev A, Eong KGA. Effect of preoperative counseling on fear from visual sensations during phacoemulsification under topical anesthesia. $J$ Cataract Refract Surg. 2011;37(5):814-818. doi:10.1016/j.jcrs.2010.11.041

26. Lambert E, Carey S. Practice guideline recommendations on perioperative fasting: a systematic review. J Parenter Enteral Nutr. 2016;40(8):1158-1165. doi:10.1177/0148607114567713

27. Kumar CM, Seet E, Eke T, Irwin MG, Joshi GP. Peri-operative considerations for sedation-analgesia during cataract surgery: a narrative review. Anaesthesia. 2019;74(12):1601-1610. doi:10.1111/anae. 14845

28. Fawcett WJ, Thomas M. Pre-operative fasting in adults and children: clinical practice and guidelines. Anaesthesia. 2018;74(1):83-88. doi:10.1111/anae. 14500

29. Seet E, Kumar CM, Eke T, Joshi GP. Starving patients before cataract surgery under regional anesthesia: needed or not? Anesth Analg. 2018;127(6):1448-1451. doi:10.1213/ANE.0000000000003504

30. Vallance JH, Ahmed M, Dhillon B. Cataract surgery and consent; recall, anxiety, and attitude toward trainee surgeons preoperatively and postoperatively. J Cataract Refract Surg. 2004;30(7):1479-1485. doi:10.1016/j.jcrs.2003.11.050

31. Heard JA, Zacarias AAG, Lawrence AT, et al. A prospective observational cohort study to evaluate patients' experience during sequential cataract surgery under monitored anesthesia care and topical anesthesia. Medicine. 2020;99(47):e21834. doi:10.1097/ MD.0000000000021834

32. Ługowska D, Konopinska J, Mariak Z, Obuchowska I. Comparison of subjective preoperative experiences of patients before first- or second-eye cataract surgeries. Clin Ophthalmol. 2020;14:2883-2889. doi:10.2147/OPTH.S270196

33. Konopinska J, Ługowska D, Mariak Z, Obuchowska I. Comparison of auditory sensations in patients who underwent cataract phacoemulsification surgery in the first and second eye. Sci Rep. 2021;11 (1):10026. doi:10.1038/s41598-021-89594-6

34. Pager CK. Randomised controlled trial of preoperative information to improve satisfaction with cataract surgery. Br J Ophthalmol. 2005;89 (1):10-13. doi:10.1136/bjo.2004.048637

35. Yu JG, Ye T, Huang Q, et al. Comparison between subjective sensations during first and second phacoemulsification eye surgeries in patients with bilateral cataract. J Ophthalmol. 2016;2016:6521567. doi:10.1155/2016/6521567

36. Adatia FA, Munro M, Jivraj I, Ajani A, Braga-Mele R. Documenting the subjective patient experience of first versus second cataract surgery. J Cataract Refract Surg. 2015;41(1):116-121. doi:10.1016/ j.jcrs.2014.04.041

37. Vahn MA, Ogunnaike BO, Joshi GP, Warltier D. Sedation and anesthesia care for ophthalmologic surgery during local/regional anesthesia. Anesthesiology. 2007;107:502-508. doi:10.1097/01. anes.0000278996.01831.8d

38. Popovic M, Schlenker MB, Goldshtein D, Rai A, El-defraway S. Preoperative fasting for ambulatory cataract surgery: a systematic review. Can J Ophthalmol. 2019;54:145-149. doi:10.1016/j. jcjo.2018.05.011

39. Lee RMH, Thompson JR, Eke T. Severe adverse events associated with local anaesthesia in cataract surgery: 1 year national survey of practice and complications in the UK. Br J Ophthalmol. 2016;100 (6):772-776. doi:10.1136/bjophthalmol-2015-307060

40. Gong DH, Liu JF, Zhao X, Zhang L. The effect of nursing intervention on preoperative cataract. Medicine. 2018;97(42):e12749. doi:10.1097/MD.0000000000012749
41. Koolwijk J, Fick M, Selles C, et al. Outpatient cataract surgery incident and procedural risk analysis do not support current clinical ophthalmology guidelines. Ophthalmology. 2015;122(2):281-287. doi:10.1016/j.ophtha.2014.08.030

42. Habib NE, Mandour NM, Balmer HGR. Effect of midazolam on anxiety level and pain perception in cataract surgery with topical anesthesia. J Cataract Refract Surg. 2004;30(2):437-443. doi:10.1016/S0886-3350(03)00557-1

43. Ismail SA, Mowafi HA. Melatonin provides anxiolysis, enhances analgesia, decreases intraocular pressure, and promotes better operating conditions during cataract surgery under topical anesthesia. Anesth Analg. 2009;108(4):1146-1151. doi:10.1213/ ane. $0 \mathrm{~b} 013 \mathrm{e} 3181907 \mathrm{ebe}$

44. Khezri MB, Merate H. The effects of melatonin on anxiety and pain scores of patients, intraocular pressure, and operating conditions during cataract surgery under topical anesthesia. Indian J Ophthalmol. 2013;61(7):319-324. doi:10.4103/0301-4738.99637

45. Morrell G. Effect of structured preoperative teaching on anxiety levels of patients scheduled for cataract surgery. Insight. 2001;26 (1):4-9. doi:10.1067/min.2001.113201

46. Pager CK, McCluskey PJ. Surgeons' perceptions of their patients' priorities. J Cataract Refract Surg. 2004;30(3):591-597. doi:10.1016/ S0886-3350(03)00671-0

47. Spina J. The fear of cataract extraction: mental health aspects of a geriatric health problem. Clin Gerontol J Aging Ment Health. 1984;2(4):68-70.

48. O'Malley TP, Newmark TS, Rothman MI, Strassman HD. Emotional aspects of cataract surgery. Int J Psychiatry Med. 1990;19(1):85-89. doi:10.2190/XWD0-TQ3G-D14V-5TFA

49. Morgan LW, Schwab IR. Informed consent in senile cataract extraction. Arch Ophthalmol. 1986;104(1):42-45. doi:10.1001/ archopht.1986.01050130052018

50. Tan JF, Tay LK, Ng LH. Video compact discs for patient education: reducing anxiety prior to cataract surgery. Insight. 2005;30(4):16-21.

51. Tipotsch-Maca SM, Varsits RM, Ginzel C, Vecsei-Marlovits PV. Effect of a multimedia-assisted informed consent procedure on the information gain, satisfaction, and anxiety of cataract surgery patients. J Cataract Refract Surg. 2016;42(1):110-116. doi:10.1016/ j.jcrs.2015.08.019

52. Ahmed KJ, Pilling JD, Ahmed K, Buchan J. Effect of a patient-information video on the preoperative anxiety levels of cataract surgery patients. $J$ Cataract Refract Surg. 2019;45(4):475-479. doi:10.1016/j.jcrs.2018.11.011

53. Zhang MH, Haq ZU, Braithwaite EM, Simon NC, Riaz KM. A randomized, controlled trial of video supplementation on the cataract surgery informed consent process. Graefes Arch Clin Exp Ophthalmol. 2019;257(8):1719-1728. doi:10.1007/s00417-019-04372-5

54. Özlü ZK, Tuğ Ö, Yayla AÇ. Inevitable problems of older people: presurgery information effect on anxiety levels in patients undergoing cataract surgery. $J$ Clin Nurs. 2016;25(9-10):1388-1394. doi:10.1111/jocn.13233

55. Newman-Casey PA, Ravilla S, Haripriya A, et al. The effect of counseling on cataract patient knowledge, decisional conflict, and satisfaction. Ophthalmic Epidemiol. 2015;22(6):387-393. doi:10.3109/09286586.2015.1066016

56. Mohammadpourhodki R, Sargolzaei MS, Basirinezhad MH. Evaluating the effect of massage based on slow stroke back massage on the anxiety of candidates for cataract surgery. Rom J Ophthalmol. 2019;63(2):146-152. doi:10.22336/rjo.2019.22

57. Keramati MDM, Sargolzaei MS, Moghadasi A, Basirinezhad MH, Mohammadpourhodki R. Evaluating the effect of slow-stroke back massage on the anxiety of candidates for cataract surgery. Int $J$ Ther Massage Bodywork. 2019;12(2):12-17.

58. Kim MS, Cho KS, Woo HM, Kim JH. Effects of hand massage on anxiety in cataract surgery using local anesthesia. $J$ Cataract Refract Surg. 2001;27(6):884-890. doi:10.1016/S0886-3350(00)00730-6 
59. Nazari R, Ahmadzadeh R, Mohammadi S, Kiasari J. Effect of hand massage on anxiety in patients undergoing ophthalmology surgery using local anaesthesia. J Caring Sci. 2012;1:129-134. doi:10.5681/ jcs.2012.019

60. Çavdar AU, Yılmaz E, Baydur H. The effect of hand massage before cataract surgery on patient anxiety and comfort: a randomized controlled study. J Perianesth Nurs. 2020;35(1):54-59. doi:10.1016/j. jopan.2019.06.012

61. Farahani MF, Zamenjani MN, Nasiri M, Shamsikhani S, Purfarzad Z, Harorani M. Effects of extremity massage on preoperative anxiety: a three-arm randomized controlled clinical trial on phacoemulsification candidates. J Perianesth Nurs. 2020;35(3):277-282. doi:10.1016/j. jopan.2019.10.010

62. Field T, Hernandez-Reif M, Diego M, Schanberg S, Kuhn C. Cortisol decreases and serotonin and dopamine increase following massage therapy. Int $J$ Neurosci. 2005;115(10):1397-1413. doi:10.1080/ 00207450590956459

63. Guerrier G, Abdoul H, Jilet L, et al. Musical intervention reduces anxiety-related hypertensive events during cataract surgery: a randomized controlled trial. Perioper Care Oper Room Manag. 2020;20:100126. doi:10.1016/j.pcorm.2020.100126

64. Merakou K, Varouxi G, Barbouni A, et al. Blood pressure and heart rate alterations through music in patients undergoing cataract surgery in Greece. Ophthalmol Eye Dis. 2015;7:7-12. doi:10.4137/OED. S20960

65. Bringman H, Giesecke K, ThÖRne A, Bringman S. Relaxing music as pre-medication before surgery: a randomised controlled trial. Acta Anaesthesiol Scand. 2009;53(6):759-764. doi:10.1111/j.13996576.2009.01969.x
66. Bellan L, Gooi A, Rehsia S. The misericordia health centre cataract comfort study. Can J Ophthalmol. 2002;37(3):155-160. doi:10.1016/ S0008-4182(02)80057-6

67. Muddana SK, Hess OM, Sundar S, Venkatesh R. Preoperative and perioperative music to reduce anxiety during first-time phacoemulsification cataract surgery in the high-volume setting: randomized controlled trial. J Cataract Refract Surg. 2020. doi:10.1097/j. jcrs.0000000000000485

68. Wiwatwongwana D, Vichitvejpaisal P, Thaikruea L, et al. The effect of music with and without binaural beat audio on operative anxiety in patients undergoing cataract surgery: a randomized controlled trial. Eye. 2016;30(11):1407-1414. doi:10.1038/eye.2016.160

69. Choi S, Park SG, Bellan L, Lee HH, Chung SK. Crossover clinical trial of pain relief in cataract surgery. Int Ophthalmol. 2018;38 (3):1027-1033. doi:10.1007/s10792-017-0554-y

70. Camara JG, Ruszkowski JM, Worak SR. The effect of live classical piano music on the vital signs of patients undergoing ophthalmic surgery. Medscape J Med. 2008;10(6):149.

71. Knight WEJ, Rickard NS. Relaxing music prevents stress-induced increases in subjective anxiety, systolic blood pressure, and heart rate in healthy males and females. J Music Ther. 2001;38(4):254-272. doi:10.1093/jmt/38.4.254

72. Karwoski B, Kazam T, Solomon J. Music in the operating room and patient anxiety during catarac surgery. Invest Ophthalmol Vis Sci. 2010;51:5384.

73. Cruise CJ, Chung F, Yogendran S, Little DA. Music increases satisfaction in elderly outpatients undergoing cataract surgery. Can J Anaesth. 1997;44(1):43-48. doi:10.1007/BF03014323
Psychology Research and Behavior Management

\section{Publish your work in this journal}

Psychology Research and Behavior Management is an international, peer-reviewed, open access journal focusing on the science of psychology and its application in behavior management to develop improved outcomes in the clinical, educational, sports and business arenas. Specific topics covered in the journal include: Neuroscience, memory and decision making; Behavior modification and management; Clinica applications; Business and sports performance management; Social and developmental studies; Animal studies. The manuscript management system is completely online and includes a very quick and fair peer-review system, which is all easy to use. Visit http://www. dovepress.com/testimonials.php to read real quotes from published authors. 